\title{
Erratum to: Therapeutic assessment of chloroquine-primaquine combined regimen in adult cohort of Plasmodium vivax malaria from a tertiary care hospital in southwestern India
}

\author{
Kumar Rishikesh', Asha Kamath², Manjunatha H. Hande1, Sudha Vidyasagar' ${ }^{1}$, Raviraja V. Acharya ${ }^{1}$, \\ Vasudeva Acharya', Jayaprakash Belle ${ }^{1}$, Ananthakrishna B. Shastry ${ }^{1}$ and Kavitha Saravu ${ }^{1 *}$
}

\section{Erratum to: Malar J (2015) 14:310 \\ DOI 10.1186/s12936-015-0824-y}

The authors of the original article [1] have recently noticed that the published paper contained some errors.

In Table 2, 'Life table showing estimates of risk of therapeutic failure during 28 days follow-up in cohort of $P$. vivax monoinfection patients from southwestern India treated with chloroquine $(25 \mathrm{mg} / \mathrm{kg}$ over 3 days) followed by primaquine $(0.25 \mathrm{mg} / \mathrm{kg}$ daily for 14 days)', the column "IR (interval risk)" should have read "CSP (cumulative survival probability)". Table 2 is correctly displayed in this erratum.

Further, in the first paragraph of the 'Discussion' section, another case report should have been mentioned in the final sentence, to read as follows: "Nonetheless, of the published literature from India, only two case reports dating back over two decades confirms CQ failure in P. vivax despite having adequate plasma concentration of CQ $[17,18] . "$

A new Reference 18 [2] should have been included and the subsequent references renumbered to 19-26.

\begin{tabular}{|c|c|c|c|c|c|}
\hline Days & $\begin{array}{l}\text { Subjects } \\
\text { at risk }\end{array}$ & $\begin{array}{l}\text { Lost to } \\
\text { follow up }\end{array}$ & $\begin{array}{l}\text { Therapeutic } \\
\text { failure }\end{array}$ & CSP & CITF \\
\hline 0 & 125 & 0 & 0 & 1.00 & 0 \\
\hline 2 & 125 & 0 & 0 & 1.00 & 0 \\
\hline 3 & 125 & 0 & 1 & 0.99 & 0.01 \\
\hline 7 & 124 & 3 & 0 & 0.99 & 0.01 \\
\hline 14 & 121 & 0 & 0 & 0.99 & 0.01 \\
\hline 21 & 121 & 0 & 0 & 0.99 & 0.01 \\
\hline 28 & 121 & 0 & 0 & 0.99 & 0.01 \\
\hline
\end{tabular}

CSP cumulative survival probability, CITF cumulative incidence of therapeutic failure

\section{Author details}

${ }^{1}$ Department of Medicine, Kasturba Medical College, Manipal University, Madhav Nagar, Manipal 576104, Karnataka, India. ${ }^{2}$ Department of Community Medicine, Kasturba Medical College, Manipal University, Madhav Nagar, Manipal, India.

\footnotetext{
*Correspondence: kavithasaravu@gmail.com

${ }^{1}$ Department of Medicine, Kasturba Medical College, Manipal University, Madhav Nagar, Manipal 576104, Karnataka, India

Full list of author information is available at the end of the article
}

Published online: 03 February 2016

The online version of the original article can be found under doi:10.1186/s12936-015-0824-y.

Reference

1. Rishikesh, et al. Malar J. 2015;14:310. doi:10.1186/s12936-015-0824-y.

2. Garg M, Gopinathan N, Bodhe P, Kshirsagar NA. Vivax malaria resistant to chloroquine: case reports from Bombay. Trans R Soc Trop Med Hyg. 1995;89:656-7. 